\section{Response to: 'Inflammation in SLE-PAH: good news or not?' by Junyan Qian et al}

Thank you very much for your interest in our article 'Two distinct clinical phenotypes of pulmonary arterial hypertension secondary to systemic lupus erythematosus', and we are glad to answer the question 'Inflammation in SLE-PAH: good news or not?' as below.

First, referral bias may exist and contribute to the different outcome. As an example, the Peking Union Medical College Hospital (PUMCH) cohort has more patients with pulmonary arterial hypertension secondary to systemic lupus erythematosus (SLE-PAH) with vasculopathic subtype. ${ }^{1}$ Among these patients, the 3-year survival is precisely in line with our two cohorts, ${ }^{1}{ }^{2}$ suggesting those SLE with 'pure' PAH are more homogeneous. Further analysing the more heterogeneous vasculitic subtype, the baseline manifestations and SLE disease activity index (SLEDAI) of our data vary. We totally agree that such patients with more systemic inflammatory components would be a better responder to immunosuppressive therapies, and some patients may even experience a reversible PAH course. ${ }^{3-5}$ Nevertheless, when talking about all-cause mortality, it makes sense that a patient who had a pronounced lupus nephritis (LN) or neuropsychiatric systemic lupus nephritis (NPSLE) or haematological manifestations on top of PAH will have a higher probability of poorer outcome. ${ }^{6}$ Another scenario is that when such patients underwent aggressive immunosuppressive therapy and complicated with infection, they tend to be more vulnerable to haemodynamically unstable. In other words, for those more heterogeneous vasculitic SLE-PAH subtype, baseline parameters and other confounders such as comorbidities, complications and treatment protocols should be scrutinised before a definitive conclusion can be made. It seems indisputable that clinical trials should be carried out on such patients in order to justify the appropriate combination of immunosuppressive therapy and PAH-targeted treatment, and improve the overall outcome.

\section{Fangfang Sun, ${ }^{1}$ Yunxia Lei, ${ }^{2}$ Xiao Zhang, ${ }^{2}$ Shuang Ye ${ }^{1}$}

${ }^{1}$ Department of Rheumatology, School of Medicine, Ren Ji Hospital South Campus, Shanghai Jiaotong University, Shanghai, China

${ }^{2}$ Department of Rheumatology, Guangdong General Hospital, Guangzhou, China
Correspondence to Professor Shuang Ye, Department of Rheumatology, School of Medicine, Ren Ji Hospital South Campus, Shanghai Jiao Tong University, Shanghai 200001, China; ye_shuang2000@163.com

\section{Handling editor Josef S Smolen}

Contributors All authors participated in drafting and revising the response, and all authors approved the final version for publication. XZ and SY had full access to all the data in the study and take responsibility for the integrity and accuracy of the data.

Funding The authors have not declared a specific grant for this research from any funding agency in the public, commercial or not-for-profit sectors.

Competing interests None declared.

Patient consent Not required.

Provenance and peer review Commissioned; internally peer reviewed.

(C) Author(s) (or their employer(s)) 2019. No commercial re-use. See rights and permissions. Published by BMJ.

\section{Check for updates}

To cite Sun F, Lei Y, Zhang X, et al. Ann Rheum Dis 2019;78:e136.

Received 1 November 2018

Accepted 1 November 2018

Published Online First 14 November 2018

\section{Sinked}

http://dx.doi.org/10.1136/annrheumdis-2018-214605

Ann Rheum Dis 2019:78:e136. doi:10.1136/annrheumdis-2018-214647

\section{REFERENCES}

1 Qian J, Li M, Zhao J. Inflammation in SLE-PAH: good news or not? Ann Rheum Dis 2019;78:e135.

2 Sun F, Lei Y, Wu W, et al. Two distinct clinical phenotypes of pulmonary arterial hypertension secondary to systemic lupus erythematosus. Ann Rheum Dis 2019:78:148-50.

3 Yasuoka H, Shirai Y, Tamura Y, et al. Predictors of favorable responses to immunosuppressive treatment in pulmonary arterial hypertension associated with connective tissue disease. Circ J 2018;82:546-54.

4 Watanabe R, Fujii H, Shirai T, et al. Successful use of intensive immunosuppressive therapy for treating simultaneously occurring cerebral lesions and pulmonary arterial hypertension in a patient with systemic lupus erythematosus. Intern Med 2014:53:627-31.

5 Huang C, Zhang S, Tian Z, et al. Could pulmonary arterial hypertension be an active index of systemic lupus erythematosus? A successful case of SLE-PAH cured by methylprednisolone pulse therapy. Lupus 2014;23:1533-6.

6 Wu XY, Yang M, Xie YS, et al. Causes of death in hospitalized patients with systemic lupus erythematosus: a 10-year multicenter nationwide Chinese cohort. Clin Rheumatol 2018. 